\title{
NEW RESEARCH HEADQUARTERS OF THOMAS HEDLEY AND CO., LTD.
}

\author{
By DR. E. R. WILSON
}

$\mathrm{T}$ HE new Research Headquarters of Thomas Hedley and Co., Ltd., at Longbenton, Newcastle upon 'Tyne, officially opened by the Duke of Northumberland on June 14, is the result of the post-war expansion of the Company's Research Division. Only eight years ago, in 1949, modern laboratories were completed alongside Hedley's factory in City Road, Newcastle. Since that time the Research Division has grown rapidly, and with the formation of a new Basic Research Department in 1954 it became evident that much larger laboratories would soon be required. The 45 -acre site at Longbenton was chosen because it had the advantages of being out of the City and yet still accessible to public trans. portation and utilities, and it provided ample room for future expansion. The new Research Headquartors at present occupies eight acres of this area (Fig. 1).

'The new building houses the departments concerned with product research and development of both washing products and edible products. Hedley makes a sharp distinction between basic research and applied research, and (by the Company's definition) the nature of the work carried out in the new laboratories is applied research. 'The basic research for the Company continues to be carried out at the City Road laboratories, where the Basic Research Department has expanded into the space vacated by the applied research groups as they moved to I Iongbenton.

Although the Company defines the research at Longbenton as 'applied', much of it is the type of research that is commonly termed 'basic', since the work normally begins at the test-tube stage. From here it proceeds by definite steps from small-scale, glass-ware, laboratory bench reactions, in which new compounds are synthesized and evaluated for new properties, to small batch-process pilot plant equipment, and finally to small-scale continuous-process pilot plant equipment which duplicates all conditions expected in factory production.

The building is designed in two main blocks on an east-west axis with a connecting north-south block. With the exception of the rear east-west block, which houses the pilot plant area, the building is single story. It is anticipated that the remainder of the Research Division now at City Road will eventually join the group at Longbenton, and allowance has been made in the design for future expansion.

The front block is arranged so as to have executive and administrative offices on one side of the corridor with laboratories on the other side. In these laboratories, graduate chemists and their technical assistants carry out the product research work for the Company. Their purpose is to formulate all of the Company's products so that each in its field will be entirely acceptable to the consumer for performance and appeal. 'That this can be an extremely complex operation is illustrated by the fact that a synthetic detergent granule, for example, normally contains as many as twenty different chemical compounds which must be present in the correct proportion for optimum performance.

In order to make certain that formulations do represent improvements which are not only detect-

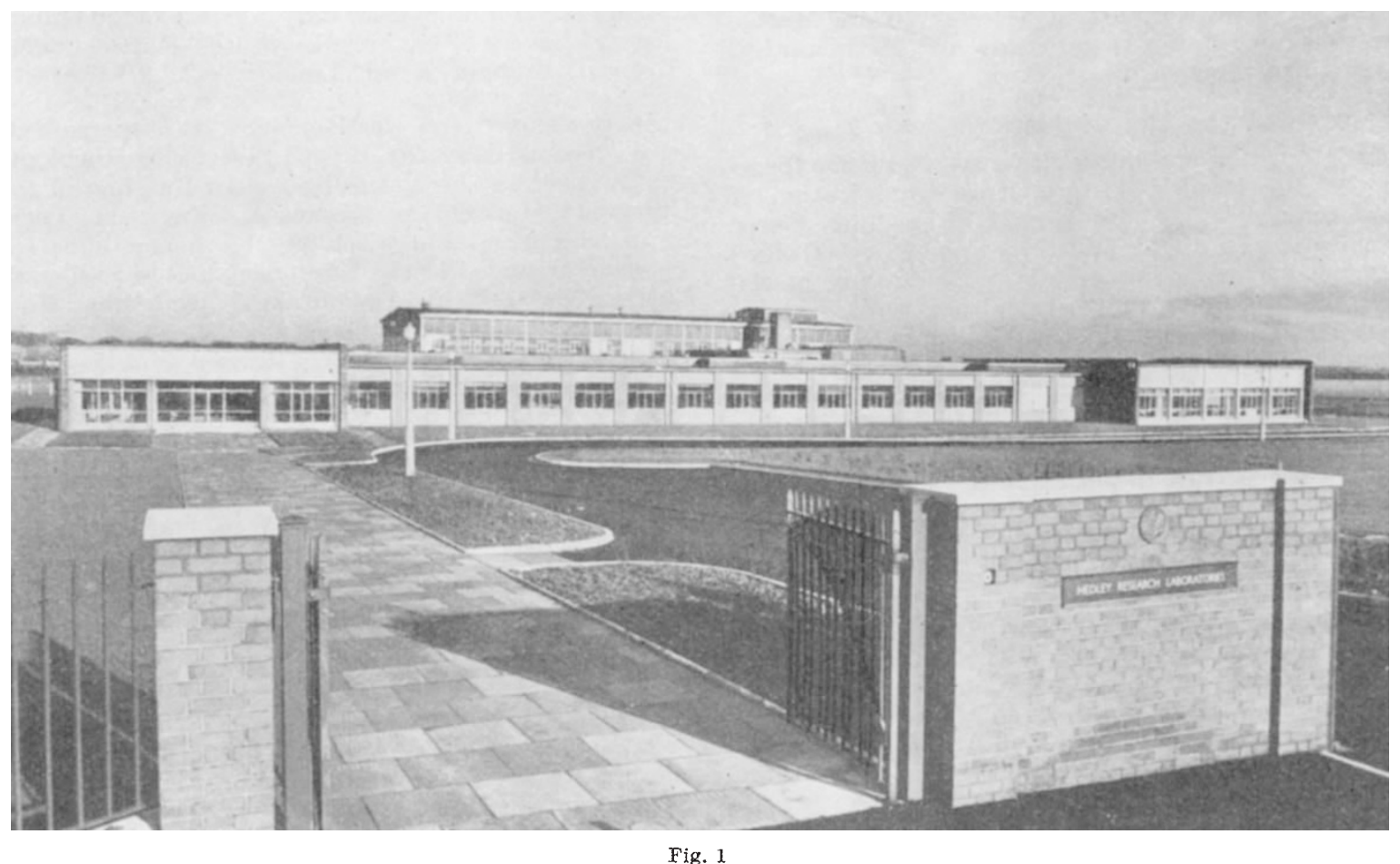


able by sensitive laboratory tests but also easily seen by the final, less exact consumer, the laboratories include a research laundry and a research bakery. In the research laundry facilities have been installed which enable the scientist to set up every conceivable condition to duplicate domestic washing procedures for experimental purposes as well as to study all types of innovation, such as new washing machines, as they appear on the market. 'Ihe same idea is behind the range of equipment in the research bakery, where all the problems confronting the baker can be duplicated and studied, and new shortening formulæ and recipes for the bakery trade formulated.

'The back, east-west block houses the pilot plant area and the development laboratories. Approximately one-third of this two-story area is clear from floor to roof so as to accommodate the larger pilot. plant equipment. Smaller pilot-plant equipment is located under the mezzanine floor which covers the remaining two-thirds of the building. The mezzanine floor itself has offices and laboratories on both sides of a central area which is equipped with benches, fume hoods and smaller pieces of development equipment.

In these laboratories problems vary considerably in magnitude. For example, the chemist may be synthesizing previously unknown compounds to test as detergents. Simultaneously, he may be developing a new chemical process for manufacturing a detergent on a commercial scale, or developing a new formula to meet certain desired performance characteristics. $\mathrm{He}$ is, in effect, responsible for both the generation of ideas leading to new products and for the development of those ideas from the laboratory bench through the pilot plant to the factory.

In order to carry out such a programme, facilities include an area under the mezzanine floor for an engineering division development group as well as various service shops. This combination permits on-the-job construction of all new pilot plant and processing equipment. The north-south connecting block between the two east-west blocks contains various constant-temperature rooms, as well as additional product research laboratories. The building also contains, in the front east-west block, a technical library which is an extension of the main library in the Basic Research Department in the City Road laboratories. Also provided are a hospital suite and a large, pleasant dining room together with a modern kitchen.

Approximately 230 of the Research Division's staff of 300 are at work in the new building, which cost more than $£ 500,000$ to build and equip. At the present time, on the production side of Hedley's business, one person out of every five is engaged in some form of research.

\title{
HATFIELD TECHNICAL COLLEGE
}

\author{
By Dr. W. A. J. CHAPMAN \\ Principal
}

$\mathrm{H}^{\wedge}$ ATEIELD Technical College has just completed the first five years of its existence. The College is a unit in the plan for Hertfordshire which includes senior colleges at Letchworth, Hatfield and Watford, associated with a chain of colleges of further education. When the plan is complete, Hatfield will have close ties with colleges at St. Albans (4 miles), Welwyn Garden City (3 miles), Hertford ( 8 miles) and Barnet ( 8 miles), to offer a comprehensive service for the central portion of the county.

The College was conceived in 1947 to be on a ninetyacre site to the south of Hatfield presented to Hert fordshire County Council by Mr. A. S. Butler, at that time chairman of the de Havilland Company, Ltd. An interesting feature of the preliminary planning was the almost complete absence of any organized service of further education in the area upon which estimates of accommodation could be based. For many years previously the de Havilland Technical School at Astwick Manor had been providing the academic facilities for the Company's apprentices, and latterly the County Council participated in its work. The remainder of the population in the area sought their educational facilities in London, to which transport facilities are good.

The work on the building started late in 1948 and it was opened for classes in 1952 as the first completely new college erected after the War. The building is of modern design with the accommodation on a single floor except at the front where, due to a sloping site, the upper floor is on the level of the rest of the building. The construction is of a framed semi-prefabricated character with a reinforced concrete frame and brick in-filling. This form of construction was dictated by the shortage of steel prevalent at that time, and the bulk of the concrete frame members were manufactured at a plant set up a few miles from the site. The accommodation originally planned included facilities for engineering, science, building, commerce and social and professional studies; but about 1950, during the course of erection, the wing containing the science laboratories was subjected to an economy measure and became deferred. This necessitated some temporary improvization by the conversion of low-level accommodation and delayed the start of science work until January 1953.

When classes commenced, except for small numbers of A.F.R.Ae.S. students, the most senior work in operation was for the third year of the Ordinary National Certificate in engineering by a feed from the de Havilland Technical School which, by an arrangement with the Ministry of Education, was conducting S.2 classes. Engineering was conducted in the two departments of works and production and technical and design, with emphasis on manufacture and design, respectively. The electrical work was shared between these departments according to its practical or professional bias. From the beginning, all first-year work in engineering was conducted at the colleges of further education as the first stage of the Authority's plan to remove progressively all work up to intermediate standard. Work in all faculties other than engineering commenced at the first year of studies with a year's delay in any serious work in science.

The growth of the demand on the College and its expansion in numbers and staff have been considerable. The support was probably stimulated by the development of the new towns at Hatfield and Welwyn Garden City, and the increases in population 